\section{sciendo}

DOI: 10.2478/ncr-2018-0003

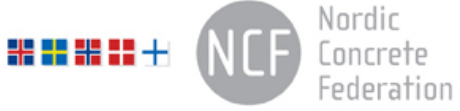

ISSN online 2545-2819

ISSN print $\quad 0800-6377$

Received: Feb. 16, 2018

Revision received: April 19, 2018

Accepted: April 19, 2018

\title{
Frost Destruction of Concrete - A Study of the Validity of Different Mechanisms
}

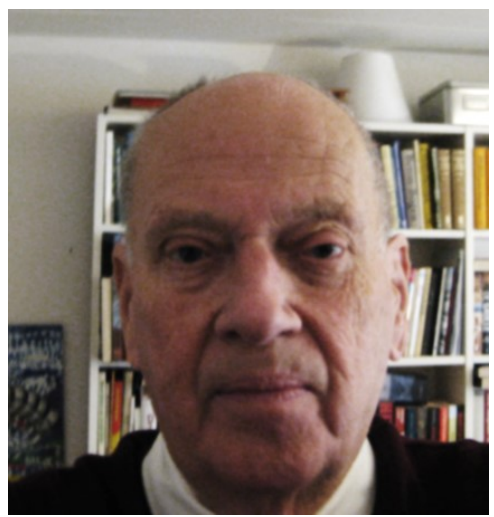

Göran Fagerlund

Professor em.

Div. Building Materials

Lund Institute of Technology

Box 118

SE-221 00 Lund

E-mail: goran.fagerlund@byggtek.lth.se

\section{ABSTRACT}

Well-known frost destruction mechanisms applicable to concrete not exposed to salt are, (1) hydraulic pressure during freezing, (2) growth of ice-bodies in capillaries during freezing. Theories behind these mechanisms are presented. A third mechanism, ice expansion during heating of frozen concrete, is put forward. The validity of a certain mechanisms is discussed by analyzing its ability to explain experimental observations.

Key words: Frost damage mechanisms, hydraulic pressure, ice growth, thermal deformation

\section{EXPERIMENTAL OBSERVATIONS}

Investigations of the validity of a certain frost destruction mechanisms are best performed on specimens that are isolated from water exchange with the environment during freeze/thaw. Typical results of such experiments are seen in Figures 1-4. All these experimental observations must be explained by the destruction theory if this is to be valid. 


\subsection{Critical water content, critical air-pore spacing}

The water content in concrete can be expressed in terms of degree of saturation, $\mathrm{S}$, where $\mathrm{S}=0$ and $\mathrm{S}=1$ correspond to complete dryness and complete saturation (all pores including air-pores and pores in aggregate water filled). Above a certain critical degree of saturation damage occurs at freezing while no damage occurs below the critical value. The critical value is independent of the number of freeze-thaw cycles and rate of freezing but might be somewhat dependent on the lowest freezing temperature. The concept critical degree of saturation is discussed in detail in [1]. An example of the experimental determination of the critical degree of saturation is shown in Figure 1, published in [1]. Each specimen had an individual water content that was kept constant during the test.

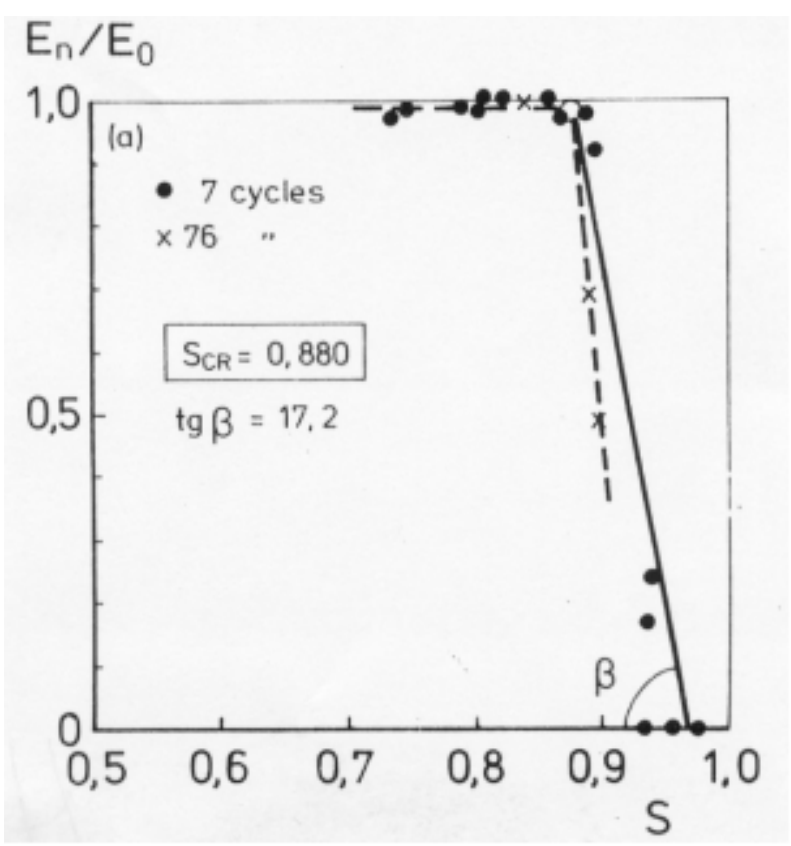

Figure 1 - Determination of the critical degree of saturation of an OPC-concrete with w/c-ratio 0.45 and $6 \%$ air. $E_{0}$ and $E_{\mathrm{n}}$ are the E-modulus before freeze/thaw and after $n$ freeze/thaw cycles [1].

The critical degree of saturation will normally not be reached until a certain fraction of the airpore system has been water-filled. The fact that the critical saturation exists indicates that there must exist a certain critical flow distance between places where water freezes and air-pores not filled by water. The critical flow distance is individual for each type of concrete but independent of the shape of the air-pore system. A theoretical analysis of the relation between the critical degree of saturation and the critical flow distance is performed in [2]. Analysis performed for an OPC-concrete with w/c-ratio 0.57 gave the critical flow distance $0.33 \mathrm{~mm}$. The critical flow distance for other types of concrete might be somewhat different.

\section{Effect of water content on length change}

Figure 2 shows measurements of length changes during freezing and thawing of two moisture sealed cement pastes with the same w/c-ratio but with two different water contents. Temperature is measured in the Centre of the specimen. The amount of frozen water is only about 4 grams 
higher in the paste with big expansion. The measurements were made in a combined calorimeter/dilatometer [3]. The following observations are made:

- Freezing is not initiated until pore water has been super-cooled to about $-5^{\circ} \mathrm{C}$. Then, temperature is rapidly increased to about $-1^{\circ} \mathrm{C}$ at the same time as the specimen expands momentarily and reversibly.

- The specimen contracts more than normal thermal contraction when the water content is below the critical value.

- The specimen expands when the water content is above the critical value.

- At thawing, the expanded specimen maintains its expanded state, or even expands a bit further, until temperature has increased to about $-10^{\circ} \mathrm{C}$ when big contraction occurs until the entire specimen is thawed.

- When the water content is above the critical value there is big permanent expansion of the specimen after complete thawing.
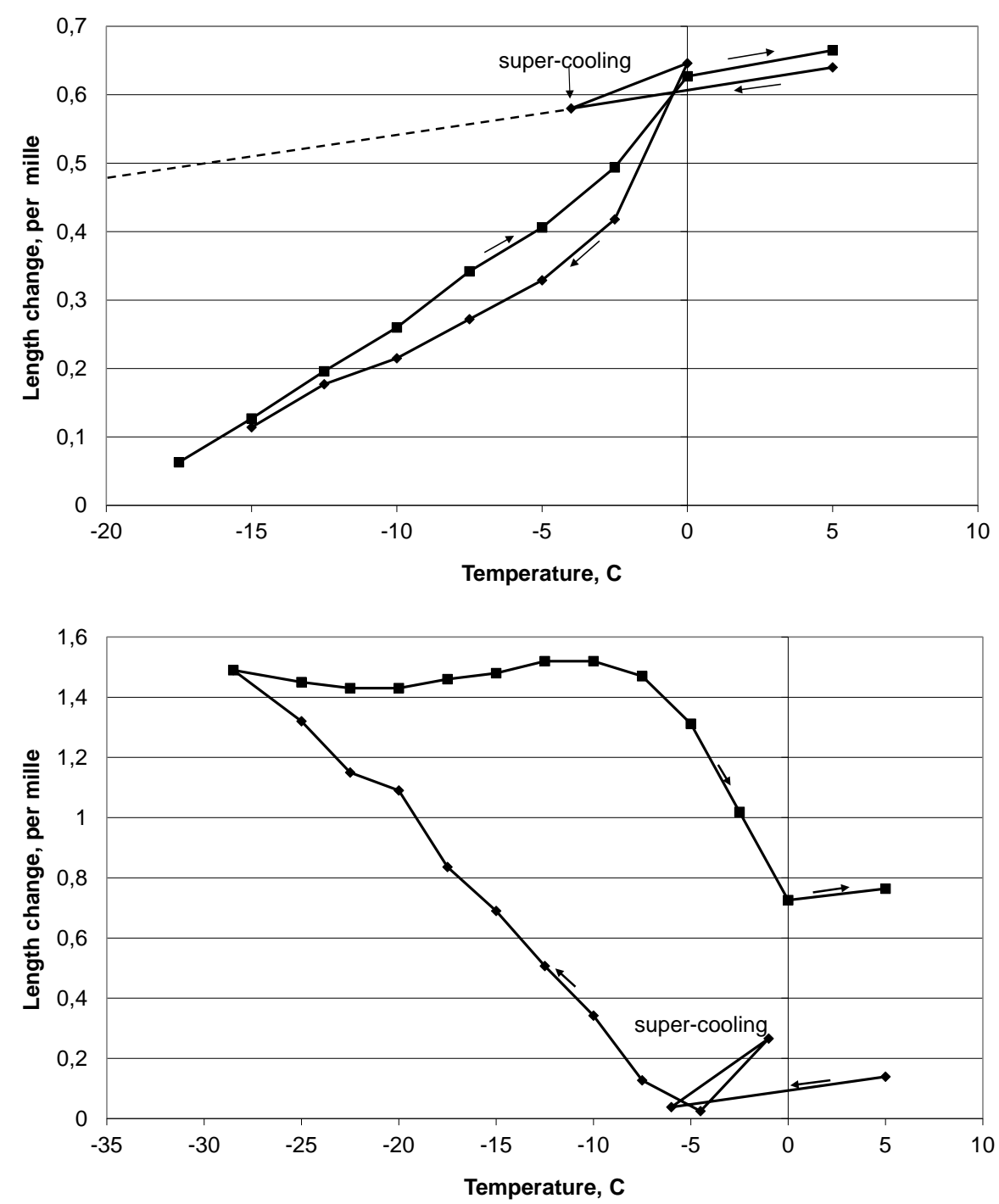

Figure 2 - Length change measurements during freezing and thawing of a non-air entrained cement paste specimen with w/c-ratio 0.83. Specimen volume, $100 \mathrm{~cm}^{3}$. Pore volume, $59 \mathrm{~cm}^{3}$. Temperature measured inside the specimen. Upper figure: Specimen saturation 0.83 which is below critical. Total volume of ice is $22 \mathrm{~cm}^{3}$ at $-10^{\circ} \mathrm{C}$. Lower figure: Specimen saturation 0.90 which is above critical. Total volume of ice is $30 \mathrm{~cm}^{3}$ at $-27^{\circ} \mathrm{C}$. 
Nordic Concrete Research - Publ. No. NCR 58 - ISSUE 1 / 2018 - Article 3, pp. 35-54

\section{Effect of temperature curve and air on length change}

Measurements of length changes of moisture sealed concrete specimens frozen and thawed in air are shown in Figure 3 [4]. Temperature was measured on the surface of the specimen. Temperature in the freezing cabinet was held constant at $-15^{\circ} \mathrm{C}$ and $-30^{\circ} \mathrm{C}$ during 12 hours. The specimen surface rapidly adopted the same constant temperatures. The following observations are made:

- Non-air-entrained concrete with water content above critical: the concrete expands during freezing. After 7 hours the specimen expands rapidly due to terminated super-cooling. At further cooling, expansion continues. When temperature is held constant at $-15^{\circ} \mathrm{C}$ and at $-30^{\circ} \mathrm{C}$ expansion immediately stops. When temperature continues to decrease, expansion continues.

- Air-entrained concrete with water content below critical: the concrete contracts during freezing. When temperature is held constant at $-15^{\circ} \mathrm{C}$ and $-30^{\circ} \mathrm{C}$ contraction immediately stops. When temperature continues to decrease, contraction continues.
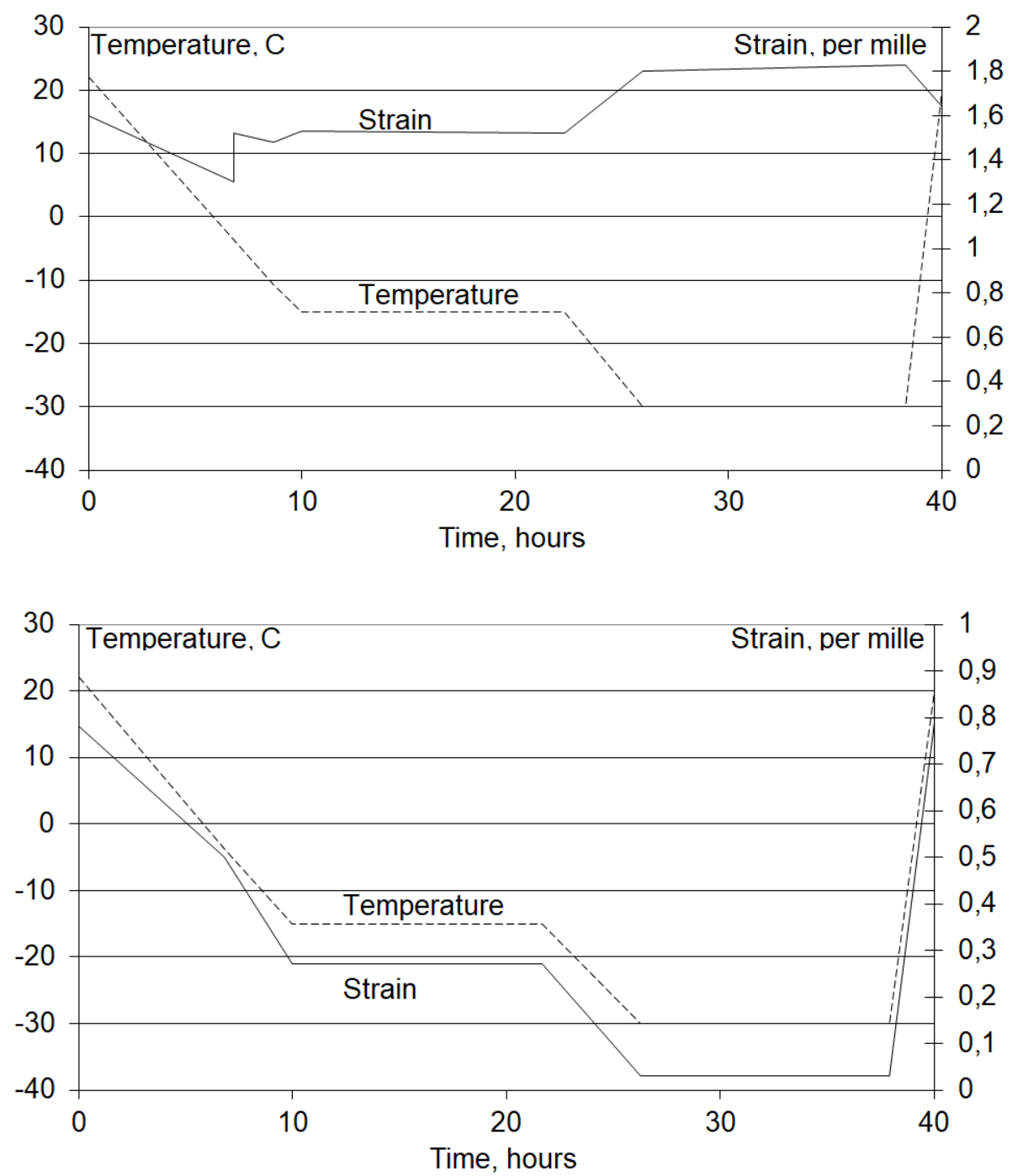

Figure 3 - Length changes versus temperature curve for concrete with water-cement ratio 0.60. Temperature measured on the specimen surface. Data from [4]. Upper figure: non-air-entrained concrete. Lower figure: air-entrained concrete, air content $6 \%$. 
More examples of this type of effect of the temperature curve on length change of moisture sealed concrete are found in [4].

\section{Effect of temperature-time curve on ice formation}

An example of the amount of ice in concrete as function of temperature and time is shown in Figure 4, [4]. The following observations are made:

- When temperature lowering halts, ice formation immediately stops

- When temperature lowering is resumed, ice formation immediately re-starts.

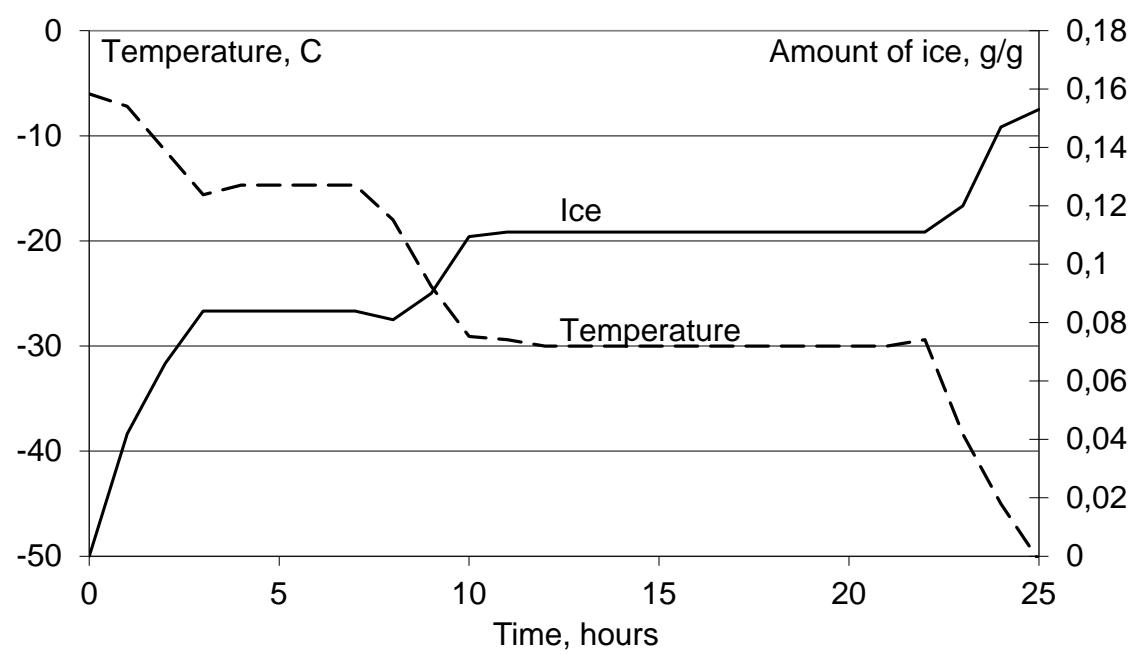

Figure 4 - Relation between temperature-time curve and ice formation. w/c-ratio 0.40. No air entrainment. Data from [4].

\section{Hysteresis between ice formation and ice melting}

A result of a calorimeter measurement of ice formation and melting is shown in Figure 5, [4]. Temperature was measured in the calorimeter compartment. The specimen temperature is somewhat higher during cooling and somewhat lower during heating due to time lag between calorimeter and specimen. There is big hysteresis between the amount of ice formed and ice melted at all temperatures. The reason is that water is super-cooled in isolated capillaries during the cooling phase while it melts at a temperature which corresponds to the pore radius. When temperature is about $-45^{\circ} \mathrm{C}$ no super-cooling exists but water freezes homogeneously.

Results show that the rate of freezing has no influence on the amount of ice formed at a given temperature [4]. 


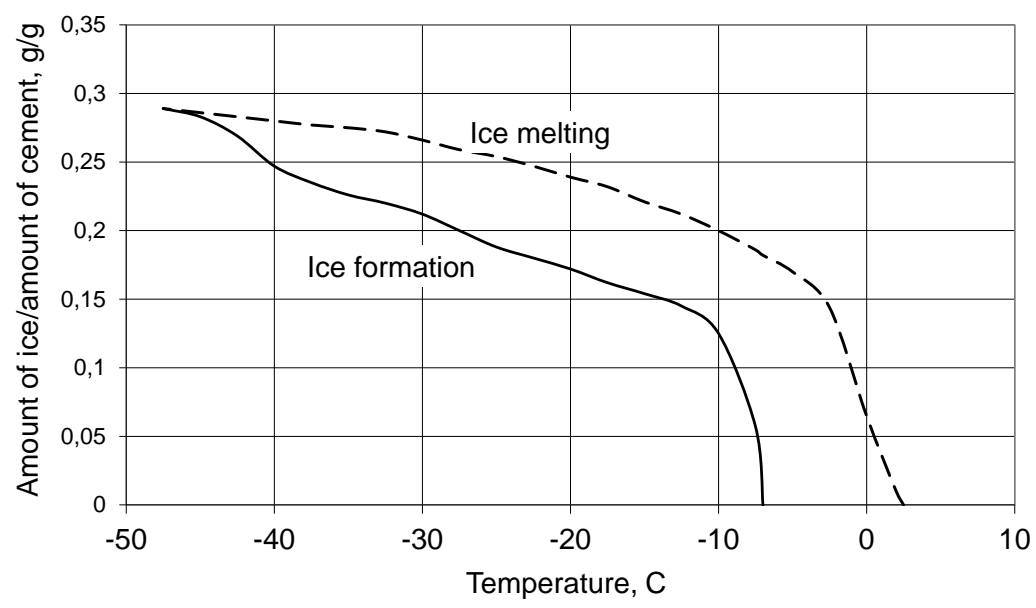

Figure 5 - Example of the hysteresis between ice formation and ice melting. w/c-ratio 0.60, no air entrainment. Freezing rate $3.6^{\circ} \mathrm{C} / \mathrm{h}$ and $7.8^{\circ} \mathrm{C} / \mathrm{h}$. Data from [4]. Temperature measured in the calorimeter compartment.

2. DESTRUCTION MECHANISM - HYDRAULIC PRESSURE

\section{1} Theory

When water freezes in capillaries and in water-filled air-pores, excess water caused by the 9\% increase in water volume when transformed into ice has to flow to the nearest air-filled spaces. There are two parts in the freezing process during which hydraulic pressure might be relevant: Part 1: When temperature is gradually lowered after termination of super-cooling there will be a gradual increase in ice formation. The rate of ice formation is normally rather low, but permeability is also low due to ice formation. At high degree of saturation the only possibility for excess water to escape is through the narrow gel pore system since gel pore water is unfreezable. Increased amount of frozen water can therefore be accompanied by continuous expansion provided the water content is high.

Part 2: When initial super-cooling is interrupted, temperature rapidly increases and a certain amount of water freezes in a very short time.

\section{Part 1: Gradually lowered temperature and increase in ice formation}

Water transport takes place in a narrow and partly ice-filled pore system and it will exert pressure to the pore walls. Fracture occurs when the pressure exceeds the tensile strength of the cement paste. When this happens, the flow distance $t$ exceeds a critical value $t_{\mathrm{CR}}(\mathrm{m})$. The mechanism was presented and discussed by Powers [5]. The model in Figure 6 is used for calculating the pressure and the critical flow distance. 


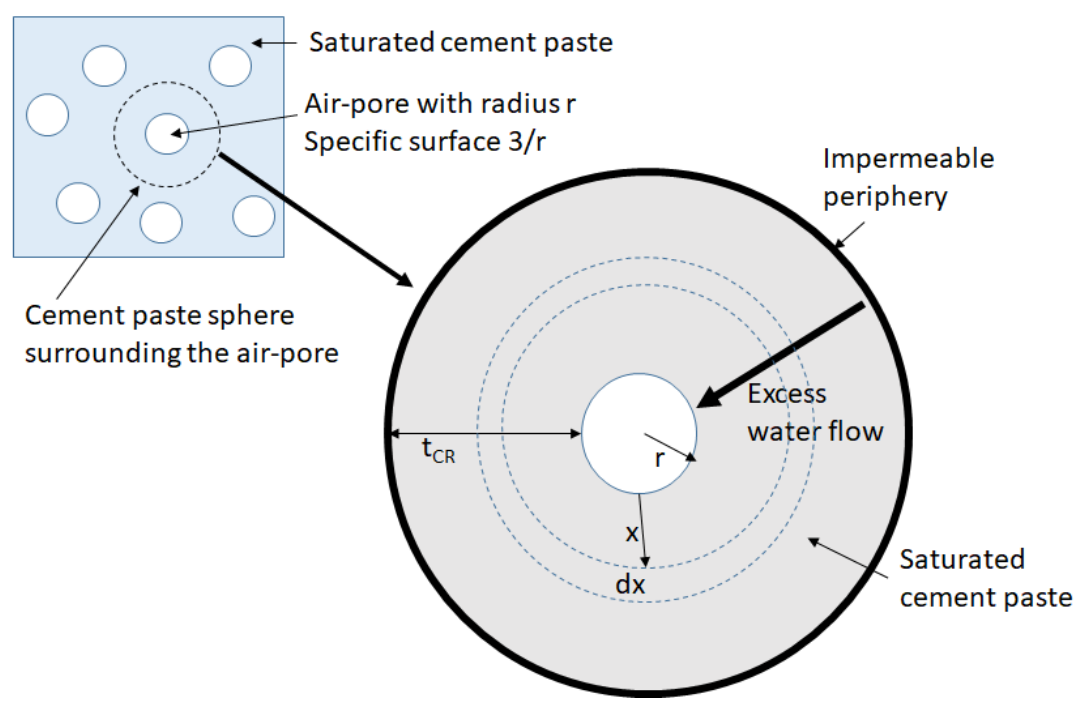

Figure 6 - Model for calculating the hydraulic pressure: saturated spherical cement paste shell with impermeable outer surface surrounding an empty spherical air-pore with radius $r$.

Water can only flow towards the void, since water outside the sphere has to move to voids in neighboring spheres. The rate of total excess water $W_{x}\left(\mathrm{~m}^{3} / \mathrm{s}\right)$ formed within the outer shell with thickness $t_{\mathrm{CR}}-x$ is:

$$
W_{x}=0,09 \cdot \frac{d w_{f}}{d \theta} \cdot \frac{d \theta}{d t} \cdot\left[\frac{4 \pi}{3}\left(t_{C R}+x\right)^{3}-\frac{4 \pi}{3}(r+x)^{3}\right]
$$

Where,

$d w_{\mathrm{f}} / \mathrm{d} \theta \quad$ ice formation as function of the freezing temperature, $\mathrm{m}^{3} /\left(\mathrm{m}^{3} \cdot\right.$ degree $)$

$d \theta / d t \quad$ rate of temperature change in cement paste during freezing, degree/s

$t_{\mathrm{CR}} \quad$ the critical shell thickness, i.e. the critical flow distance, $\mathrm{m}$

The area $A_{\mathrm{x}}\left(\mathrm{m}^{2}\right)$ across which this flow takes place is:

$$
A_{x}=4 \pi \cdot(r+x)^{2}
$$

Water flow creates pressure that is described by Darcy's law:

$$
W_{x}=K \cdot A_{x} \cdot \frac{d P}{d x} A=\pi r^{2}
$$

Where,

$d P / d x \quad$ pressure gradient, $\mathrm{Pa} / \mathrm{m}$

$K \quad$ permeability coefficient, $\mathrm{m}^{2} /(\mathrm{Pa} \cdot \mathrm{s})$

Pressure is zero at the periphery of the void. It is highest at the outer periphery. Inserting values for $W_{\mathrm{x}}$ and $A_{\mathrm{x}}$ in Equation (1) and integrating over the shell thickness gives the following expression for the maximum pressure: 


$$
P_{\max }=\frac{0,09 \frac{d w_{f}}{d \theta} \cdot \frac{d \theta}{d t}}{3 K} \cdot \int_{0}^{t_{C R}} \frac{\left(r+t_{C R}\right)^{3}-(r+x)^{3}}{(r+x)^{2}} d x
$$

The critical flow distance is obtained when max pressure equals the tensile strength $f_{\mathrm{t}}$ of the cement paste; $P_{\max }=f_{\mathrm{t}}$. Solution of Equation (4) gives the following expression for the critical flow distance (the radius $r$ of the void is exchanged for its specific surface $\alpha$, i.e. $r=3 / \alpha$ ):

$$
t_{C R}^{2}\left(\frac{t_{C R} \cdot \alpha}{9}+\frac{1}{2}\right)=\frac{f_{t} \cdot K}{0,09 \frac{d w_{f}}{d \theta} \cdot \frac{d \theta}{d t}}
$$

The validity of the hydraulic pressure theory can be checked by introducing data for the parameters on the right hand side of the equation and thereby calculating the value of the critical flow distance. The calculated value is compared with the experimentally determined value. Agreement between the two values is an indication of the validity of the theory. There are three obstacles:

1. The critical flow distance must be known.

2. The specific surface of the air-filled part of the air-pore system when $t_{C R}$ is reached must be known.

3. The permeability of the partly frozen cement paste must be known.

The critical flow distance can be calculated from an experimentally determined value of the critical degree of saturation. The calculation also gives the value of the "critical specific surface" $\alpha$ corresponding to the critical flow distance. The only information required is the air-pore size distribution. The method is described in [2]. The following critical specific surface was obtained for an OPC-concrete with water-cement ratio 0.57: $\alpha=9.3 \mathrm{~mm}^{-1}=9.3 \cdot 10^{3} \mathrm{~m}^{-1}$. Inserting this value and the observed critical flow distance $0.33 \mathrm{~mm}=0.33 \cdot 10^{-3} \mathrm{~m}$ gives:

$$
9.2 \cdot 10^{-8}=\frac{f_{t} \cdot K}{0,09 \cdot \frac{d w_{f}}{d \theta} \cdot \frac{d \theta}{d t}} m^{2}
$$

All parameters except the permeability can be experimentally determined. Uniaxial tensile strength of cement paste with w/c-ratio 0.57 is at least $6 \mathrm{MPa}$ (tensile strength of the solid material on micro-level is about $200 \mathrm{MPa}$ [7]. The strength is reduced by porosity, $P$, according to the following approximate relation $f_{\mathrm{t}} \approx 200(1-P)^{3} \mathrm{MPa}$, where $\mathrm{P} \approx 0.6$. Thus $f_{\mathrm{t}} \approx 12 \mathrm{MPa}$. This value is further halved due to possible effects of micro-defects). Experiments show that $d w_{\mathrm{f}} / d \theta \approx 10^{-3} \mathrm{~m}^{3} / \mathrm{m}^{3}$. degree [4]. This value is valid during a big temperature interval for a concrete with w/c-ratio 0.60 once the rapid ice formation after super-cooling has occurred, see Figure 5. The value is not influenced by the freezing rate, which was shown experimentally. The freezing rate used for determination of $t_{\mathrm{CR}}$ was $d \theta / d t \approx 10^{-3}$ degree/s (3,6 degree/hour). This is representative for the freezing rate of outdoor air. Then, the following maximum permeability is needed for obtaining the actual observed critical flow distance:

$$
K=\frac{9.2 \cdot 10^{-8} \cdot 0,09 \cdot 10^{-3} \cdot 10^{-3}}{6 \cdot 10^{6}}=1.4 \cdot 10^{-21} \frac{\mathrm{m}^{2}}{\mathrm{~Pa} \cdot \mathrm{s}}
$$


The only pores that are not blocked by ice when a large fraction of ice has been formed are the gel pores since water in these is not freezable. According to measurements by Powers [6] the permeability of gel pores at room temperature is $7 \cdot 10^{-11}$ darcy corresponding to $7 \cdot 10^{-20}$ $\mathrm{m}^{2} /(\mathrm{Pa} \cdot \mathrm{s})$. The permeability is decreased at lowered temperature due to lower water viscosity. According to [8] the viscosity of super-cooled water at $-20^{\circ} \mathrm{C}$ is 4 times higher than at $+20^{\circ} \mathrm{C}$. Thus, the permeability of gel water at $-20^{\circ} \mathrm{C}$ is about $2 \cdot 10^{-20} \mathrm{~m}^{2} / \mathrm{Pa} \cdot \mathrm{s}$. This value is 7 times higher than the required permeability according to the hydraulic pressure theory. One cannot exclude, however, that ice in capillaries blocks water transfer from gel pores before it can reach air-filled spaces, which makes permeability even lower than for un-blocked gel pores. Therefore, the calculation of the required permeability above does not necessarily contradict the hydraulic pressure theory.

\section{Part 2: Interrupted super-cooling}

Examples of interrupted super-cooling and the accompanied rapid increase of specimen length are seen in Figures 2 and 3. The expansion shown in Figure 2 for the cement paste specimen with high degree of saturation is immediately reversed when rapid ice formation ends, which indicates that the reason for expansion is hydraulic pressure. The super-cooling is about $-6^{\circ} \mathrm{C}$ and the expansion about $0.2 \%$. The fact that contraction occurs shows that the expansion was not big enough to harm the specimen. Figure 3 (upper figure) shows big expansion of a concrete specimen when super-cooling is terminated at about $-7^{\circ} \mathrm{C}$. Also in this case the expansion is about $0.2 \%$. This is of the same order as the fracture strain of concrete.

The amount of ice formed when super-cooling is terminated can be calculated from the "instantaneous" temperature rise when super-cooling is terminated. The process is almost adiabatic. The amount of ice formed within a materials volume $V$ can then be calculated by:

$$
W_{f}=\frac{\gamma_{m} \cdot c_{m}}{\rho_{w} \cdot \Delta_{h}} \cdot \Delta T \cdot V \approx 0.006 \cdot \Delta T \cdot V
$$

Where,

$W_{\mathrm{f}} \quad$ amount of frozen water, $\mathrm{m}^{3}$

$\Delta T \quad$ instantaneous temperature rise at termination of super-cooling, $\mathrm{K}$

$\rho_{\mathrm{w}} \quad$ density of water, $1000 \mathrm{~kg} / \mathrm{m}^{3}$

$\Delta \mathrm{h} \quad$ heat of fusion of water, $333 \cdot 10^{3} \mathrm{~J} / \mathrm{kg}$

$\gamma_{\mathrm{m}} \quad$ density of material, $\approx 2200 \mathrm{~kg} / \mathrm{m}^{3}$

$c_{\mathrm{m}} \quad$ specific heat of material, $\approx 0.9 \cdot 10^{3} \mathrm{~J} /(\mathrm{kg} \cdot \mathrm{K})$

$V \quad$ materials volume within which ice formation is very rapid, $\mathrm{m}^{3}$

All parameters on the right hand side, except volume $V$ are known. $\Delta T$ is directly observed by the actual temperature-time curve. The volume of the specimen in Figure 2 is $10^{-4} \mathrm{~m}^{3}(100$ $\mathrm{cm}^{3}$ ) and the temperature rise $5^{\circ} \mathrm{C}$. Thus, the maximum amount of ice rapidly formed is $0.006 \cdot 5 \cdot 10^{-4}=3 \cdot 10^{-6} \mathrm{~m}^{3}$ or $3 \mathrm{~cm}^{3}$. This is about $6 \%$ of the total amount of water in the specimen. The volume expansion of this ice is $0.1 \cdot 3.6=0.36 \mathrm{~cm}^{3}$. The observed volume expansion is $3 \cdot 0.2 \cdot 10^{-3} \cdot 100=0.06 \mathrm{~cm}^{3}$. Thus, as expected, expansion due to hydraulic pressure is smaller than the expansion of water when it freezes.

Ice formation is initiated at some point in the specimen and is then spread by a velocity of about $10 \mathrm{~mm} / \mathrm{s}$ [9]. This means that all water in a fictitious sphere with radius $r \mathrm{~m}$ 
surrounding the point of nucleation is nucleated within time $r \cdot 1000 / 10=100 \cdot r \mathrm{~s}$. The volume of this sphere is supposed to be equal to the actual specimen volume $10^{-4} \mathrm{~m}^{3}$, which gives a fictitious radius of $2.9 \cdot 10^{-2} \mathrm{~m}$. The nucleation time is $100 \cdot 2.9 \cdot 10^{-2}=2.9 \mathrm{~s}$.

The average rate of ice formation in the sphere is:

$$
\frac{d w_{f}}{d t}=\frac{W_{f}}{V} \cdot \frac{1}{\Delta t}=\frac{3 \cdot 10^{-6}}{10^{-4}} \cdot \frac{1}{2.9}=10^{-2} \frac{m^{3}}{m^{3} \cdot s}
$$

This value is 10000 times higher than the value in Part 1 above, which is: $d w_{f} / d t=10^{-6}$ $\mathrm{m}^{3} /\left(\mathrm{m}^{3} \cdot \mathrm{s}\right)$. The two freezing rates cannot be directly compared, however, since they are valid for different materials; cement paste with w/c-ratio 0.83 and concrete with w/c-ratio 0.57. It seems obvious, however, that the rate of ice formation is considerably higher when super-cooling is interrupted than when the more slow temperature change takes place thereafter. The reason why damage does not necessarily occur is that only a small amount of ice is formed and permeability therefore still rather high.

\section{$2.2 \quad$ Relation to observations}

The following observations can be explained by the hydraulic pressure theory:

1: The existence of a critical flow distance and hence the existence of a critical degree of saturation, Figure 1.

2: The fairly good relation between the experimentally determined and the theoretically calculated critical flow distance, Equation (6) and (7).

3: the rapid expansion followed by the rapid contraction when super-cooling is terminated, Figure 2 and 3.

4: The fact that air entrainment seems to have small or no effect on frost resistance of concrete with very low water-cement ratio [10]. The permeability of this type of concrete might be so low that water is freezing more or less as in a "closed container". Theoretically, also a very small amount of freezable water might destroy concrete under such conditions.

5: The fact that porous coarse aggregate grains can destroy concrete during freezing.

The following observation seems to contradict the hydraulic pressure theory: when temperature is held constant no more ice is formed, Figure 4. Therefore, theoretically, hydraulic pressure should vanish and the specimen should contract. This does not happen however, Figure 3 (upper figure). A plausible explanation is that damage caused during freezing that precedes the halt in temperature lowering has caused so much damage to the concrete that contraction cannot take place. The fracture tensile strain of concrete is about $0.15 \%$. But as seen by Figure 3 the strain caused by freezing before the halt in temperature is about $0.2 \%$.

\section{DESTRUCTION MECHANISM-EXPANSION OF ICE DURING THAWING}

At heating of a frozen specimen damaged by frost, there might be a period of maintained expansion showing that there is no relaxation of tensile stresses. One example is seen in Figure 2 (lower figure); contraction caused by melting of ice does not start until temperature has been reduced to about $-7^{\circ} \mathrm{C}$. The reason behind this phenomenon must be the big hysteresis between 
ice formation and ice melting, Figure 5. Thermal expansion of ice is higher than that of concrete. Therefore, thermal expansion of ice before it melts might cause damage.

The coefficient of thermal expansion of a frozen material containing ice, $\alpha$, can be calculated by the following composite material expression:

$$
\alpha=\frac{\alpha_{i} \cdot V_{i} \cdot E_{i}+\alpha_{m} \cdot V_{m} \cdot E_{m}}{V_{i} \cdot E_{i}+V_{m} \cdot E_{m}}
$$

Where,

$\alpha \quad$ expansion coefficient $\mathrm{m} / \mathrm{m}$

$V \quad$ volume fraction, $\mathrm{m}^{3} / \mathrm{m}^{3}$

E E-modulus, $\mathrm{Pa}$

Indices i and m represent ice and unfrozen material.

\section{Example 1:}

The following data are valid for the cement paste in Figure 2 lower: $\alpha_{\mathrm{i}} \approx 50 \cdot 10^{-6} \mathrm{~m} / \mathrm{m}, \alpha_{\mathrm{m}} \approx 10 \cdot 10^{-6} \mathrm{~m} / \mathrm{m}, V_{\mathrm{i}}$ and $V_{\mathrm{m}}$ vary with temperature, for $-27^{\circ} \mathrm{C}$ the following values are approximately valid, $V_{\mathrm{i}}=0.30, V_{\mathrm{m}}=0.70, E_{\mathrm{i}} \approx 10 \mathrm{GPa}, E_{\mathrm{m}} \approx 3 \mathrm{GPa}\left(E_{m}=40(1-P)^{3}\right.$ GPa [11], where $P$ is paste porosity, which is about $60 \%$ ). This gives:

$$
\alpha=\frac{50 \cdot 10^{-6} \cdot 0.30 \cdot 10 \cdot 10^{9}+10 \cdot 10^{-6} \cdot 0.70 \cdot 3 \cdot 10^{9}}{0.30 \cdot 10 \cdot 10^{9}+0.70 \cdot 3 \cdot 10^{9}}=33 \cdot 10^{-6}
$$

This is more than the thermal expansion of cement paste containing no ice, which according to the contraction curve for temperature above $0^{\circ} \mathrm{C}$ is $10 \cdot 10^{-6} \mathrm{~m} / \mathrm{m}$. Additional expansion caused by ice during the temperature interval $-27^{\circ} \mathrm{C}$ to $-10^{\circ} \mathrm{C}$ for the specimen in Figure 2, provided no ice is melted, is:

$$
\Delta \varepsilon=(33-10) \cdot 10^{-6} \cdot(27-10)=0.39 \text { per mille }
$$

This is a high value. Therefore, one cannot exclude that ice expansion caused by heating will add to damage previously caused by freezing.

\section{DESTRUCTION MECHANISM - PRESSURE FROM GROWING ICE}

\subsection{Principles}

The principles for this mechanism were presented by Powers [12]. The mechanism is illustrated by Figure 7. At a certain instance below freezing temperature four water phases co-exist: (1) ice bodies completely filling coarser capillaries, (2) some ice in air-pores, (3) unfrozen water in very small capillaries and gel pores caused by freezing point depression and by super-cooling, (4) unfrozen gel water in saturated cement gel. The distance from ice in the capillary to the nearest air-pore is t. No consideration is taken below to geometrical arrangements of pores, ice and water. 


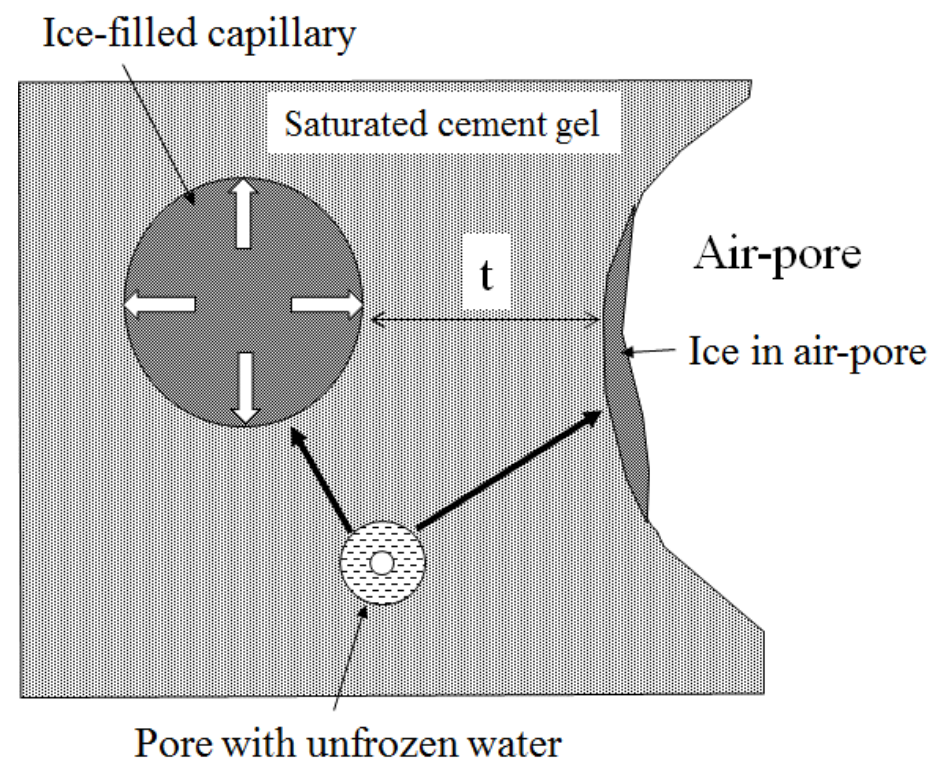

Figure 7 - Illustration of the destruction mechanism growing ice pressure. Unfilled arrows indicate pressure from growing ice. Filled arrows indicate water flow to ice bodies. The un-filled circle in pore with unfrozen water indicates drying caused by water transfer.

The system is supposed to be at equilibrium. When temperature is lowered by $d T$ the free energy of ice and water is changed. However, free energy of stress-free ice will be lower than that of unfrozen water. The change in free energy at constant pressure is:

For unfrozen bulk water:

$$
\mathrm{d} G_{w}=\left(\frac{\partial G_{w}}{\partial T}\right)_{P} \cdot \mathrm{d} T=-S_{w} \cdot \mathrm{d} T
$$

For bulk ice:

$$
\mathrm{d} G_{i}=\left(\frac{\partial G_{i}}{\partial T}\right)_{P} \cdot \mathrm{d} T=-S_{i} \cdot \mathrm{d} T
$$

Where,

$G_{\mathrm{w}}$ and $G_{\mathrm{i}} \quad$ free energy of super-cooled water and ice, $\mathrm{J} / \mathrm{mole}$

$S_{\mathrm{w}}$ and $S_{\mathrm{i}} \quad$ entropy of unfrozen water and ice, $\mathrm{J} /(\mathrm{mole} \cdot \mathrm{K})$

The difference in free energy is:

$$
\mathrm{d} G_{T}=\left(\mathrm{d} G_{w}-\mathrm{d} G_{i}\right) \cdot \mathrm{d} T=\left(-S_{w}+S_{i}\right) \cdot \mathrm{d} T
$$

\section{Example 2:}

The absolute entropies at $0^{\circ} \mathrm{C}$ for unfrozen water and ice are, $S_{\mathrm{w}} \approx 63 \mathrm{~J} /($ mole $\cdot \mathrm{K}), S_{\mathrm{i}} \approx 41$ $\mathrm{J} /($ mole $\cdot \mathrm{K})$. Temperature reduction $-\Delta T$ gives the following difference in free energy:

$$
\Delta G_{T}=(-63+41) \cdot(-\Delta T)
$$

In order the restore equilibrium, water will move from the water-filled pores towards ice bodies in ice-filled capillaries and towards ice in air-pores. The rate of water transfer is determined by 
the difference in vapour pressure between super-cooled water and ice. This is about $26 \mathrm{~Pa}$ at $-10^{\circ} \mathrm{C}$ and $22 \mathrm{~Pa}$ at $-20^{\circ} \mathrm{C}$. The water transfer takes part within the water-filled cement gel. Water is transformed into ice when arriving to the ice bodies causing these to grow and exert pressure to the pore walls. Water transfer does not stop until pressure in the ice has become so high that its free energy is equal to the free energy of unfrozen water. Before this happens the concrete might be fractured. Ice growth will also stop if water is exposed to sufficiently high under-pressure (suction). The distance water has to flow from water-filled capillaries to icefilled capillaries is very short. Therefore, for normal freezing rates, new equilibrium is rapidly reached when temperature lowering is stopped. Consequently water transport and ice growth stops.

There are two scenarios:

1. The concrete stays completely water-saturated during the freezing process. This is valid for a structure that is exposed to unfrozen water during freezing, like a foundation exposed to frost at one part and at the same time sucking ground water at a lower part, or a in a dam where the downstream part freezes while the upstream part is exposed to unfrozen water. It will also be valid for fresh concrete where the surface part freezes while the inner part of the structure contains unfrozen mixing water.

2. The concrete is isolated so that no water can enter or leave during the freezing process. This is typical for most real structures and for specimens freeze-tested in the lab.

In both cases ice growth might take place simultaneously in capillaries and in air-pores.

\section{2}

\section{Scenario 1: The concrete stays saturated. Ice growth in ice-filled capillaries}

Ice pressure is transferred to the solid pore walls through a liquid water phase. Ice bodies confined in capillaries cannot grow freely so ice formation will cause pressure against pore walls and within the ice. Ice growth exerts pressure to the water phase which in turn transfers pressure to the solid pore wall. Ice pressure will increase the free energy of ice according to the Equation below:

$$
\mathrm{d} G_{i}=\left(\frac{\partial G_{i}}{\partial T}\right)_{P} \cdot \mathrm{d} T+\left(\frac{\partial G_{i}}{\partial P}\right)_{T} \cdot \mathrm{d} P_{0}=-S_{i} \cdot \mathrm{d} T+v_{i} \cdot \mathrm{d} P_{0}
$$

Where,

$\mathrm{d} P_{0} \quad$ increase of compressive pressure in ice, $\mathrm{N} / \mathrm{m}^{2}$

$v_{\mathrm{i}} \quad$ molar volume of ice, $\mathrm{m}^{3} /$ mole $\left(v_{i}=19.6 \cdot 10^{-6} \mathrm{~m}^{3} / \mathrm{mole}\right)$

$$
d G_{w}=\left(\frac{\partial G_{w}}{\partial T}\right)_{P} \cdot \mathrm{d} T+\left(\frac{\partial G_{w}}{\partial P}\right)_{T} \cdot \mathrm{d} P_{0}=-S_{w} \cdot \mathrm{d} T+v_{w} \cdot \mathrm{d} P_{0}
$$

The following relation is valid at equilibrium. (The relation is equivalent to the Clapeyron Equation):

$$
\frac{\Delta P_{0}}{\Delta T}=\frac{\left(-S_{w}+S_{i}\right)}{v_{i}-v_{w}}
$$




\section{Example 3:}

Temperature is decreased by $5^{\circ} \mathrm{C}$ from $0^{\circ} \mathrm{C}$. Ice density and entropies are approximately constant during this small temperature change. The ice pressure when ice growth stops is:

$$
\Delta P_{0} \approx \frac{-63+41}{19.6 \cdot 10^{-6}-18 \cdot 10^{-6}} \cdot(-5)=68.8 \mathrm{MPa}
$$

Thus, very high pressure must be exerted on ice in order to stop its growth.

Note: This high pressure will only appear when the ice body is enclosed in a completely rigid, incompressible and un-fractured pore (container). In reality, the material will be fractured long before this pressure is reached.

\subsection{Scenario 2: The concrete is moisture isolated. Ice growth in capillaries}

In the normal case there is no ingress of water from outside during freezing. Water transfer to ice-bodies in capillaries will therefore cause drying of pores containing unfrozen water. This will increase the hydrostatic tension in water, decreasing its free energy:

$$
\mathrm{d} G_{w, d}=-\left(\frac{\partial G_{w}}{\partial P}\right)_{T} \cdot \mathrm{d} P_{w}=-v_{w} \cdot \mathrm{d} P_{w}
$$

Where,

$\mathrm{d} G \mathrm{w}, \mathrm{d}$ change of free energy of water caused by drying, $\mathrm{J} / \mathrm{mole}$

$\mathrm{d} P_{\mathrm{w}} \quad$ increase of hydrostatic tension in water, $\mathrm{N} / \mathrm{m}^{2}$

$v_{\mathrm{w}} \quad$ molar volume of water, $\mathrm{m}^{3} /$ mole $\left(v_{w}=18 \cdot 10^{-6} \mathrm{~m}^{3} / \mathrm{mole}\right)$

The free energy of water is changed to:

$$
\mathrm{d} G_{w}=-S_{w} \cdot \mathrm{d} T+v_{w} \cdot \mathrm{d} P_{0}-v_{w} \cdot \mathrm{d} P_{w}
$$

The free energy of ice, Equation (16), is unchanged. Equilibrium occurs when:

$$
-S_{w} \cdot \mathrm{d} T+v_{w} \cdot \mathrm{d} P_{0}-v_{w} \cdot \mathrm{d} P_{w}=-S_{i} \cdot \mathrm{d} T+v_{i} \cdot \mathrm{d} P_{0}
$$

Hydrostatic tension can be expressed in terms of relative humidity:

$$
P_{w}=-\frac{R \cdot T}{v_{w}} \cdot \ln \phi
$$

Where,

$R$ the gas constant, $8.314 \mathrm{~J} /(\mathrm{mole} \cdot \mathrm{K})$

$T$ absolute temperature, $\mathrm{K}$

$\phi \quad$ Relative Humidity (RH)

Inserting this value in Equation (22) gives the following pressure at equilibrium:

$$
\Delta P_{0}=\frac{\left(-S_{w}+S_{i}\right)}{v_{i}-v_{w}} \cdot \Delta T+\frac{8.314 \cdot T}{v_{i}-v_{w}} \cdot \ln \phi
$$




\section{Example 4:}

Temperature is decreased by $5^{\circ} \mathrm{C}$ from $0^{\circ} \mathrm{C}$. As in Example 3 relative humidity is changed to 0.97. Ice pressure in a completely rigid, incompressible ice-filled pore (container) becomes:

$$
\Delta P_{0}=\frac{(-63+41)}{(19.6-18) 10^{-6}} \cdot(-5)+\frac{8.314 \cdot 268}{(19.6-18) 10^{-6}} \cdot \ln 0.97=26 \mathrm{MPa}
$$

The calculation shows that even small drying might substantially reduce ice pressure. According to the equation, water flow stops when $\mathrm{RH}$ is reduced to $95 \%$. Drying will cause the cement paste to contract which will compensate for ice expansion. Lowering temperature further will cause bigger reduction of hydrostatic pressure causing bigger contraction.

\subsection{Ice growth in air-pores}

Water is also transferred towards ice contained in air-filled air-pores by the same mechanism as water flow to capillary ice. Air-pore ice can, however, grow in stress-free condition.

\section{Concrete stays saturated}

Ice growth will continue as long as temperature is reduced since no ice pressure is built up.

\section{Concrete is moisture isolated}

Ice growth in air pores will stop when the hydrostatic tension in unfrozen pore water is sufficiently big. Ice is not exposed to pressure. Its free energy is given by Equation (13). Free energy of water is affected by hydrostatic tension. It is:

$$
\mathrm{d} G_{w}=-S_{w} \cdot \mathrm{d} T-v_{w} \cdot \mathrm{d} P_{w}
$$

The condition for stop of ice growth, $G_{i}=d G_{w}$, becomes:

$$
\frac{\Delta P_{w}}{\Delta T}=\frac{-S_{w}+S_{i}}{v_{w}} \quad \text { or } \quad \ln \phi=-\frac{P_{w} \cdot v_{w}}{8.314 \cdot T}
$$

Example 5:

Temperature is decreased by $5^{\circ} \mathrm{C}$ from $0^{\circ} \mathrm{C}$. Ice growth stops when the hydrostatic tension in pore water and the remaining relative humidity are:

$$
\begin{aligned}
& P_{w}=\frac{-63+41}{18 \cdot 10^{-6}} \cdot(-5)=6.1 \mathrm{MPa} \\
& \ln \varphi=-\frac{6.1 \cdot 10^{6} \cdot 18 \cdot 10^{-6}}{8.314 \cdot 268} \quad \varphi=0.95
\end{aligned}
$$

\section{5}

\section{Relation to observations}

The following observations can be explained by the ice growth theory: 
1: The existence of a critical flow distance and therefore a critical degree of saturation. Since ice growth in air-pores may occur in stress-free condition water transfer will primarily go towards air-pore ice. The shorter the distance between air-pores, the smaller the pressure built up in capillaries. Since free energy of ice under pressure is higher than that of stress-free ice it might also be that pressure in ice initially formed in capillaries will be gradually reduced. Hypothetical curves of ice pressure versus air-pore spacing are shown in Figure 8. Unfortunately it is difficult to express the critical distance theoretically in similar manner as was the case for hydraulic pressure.
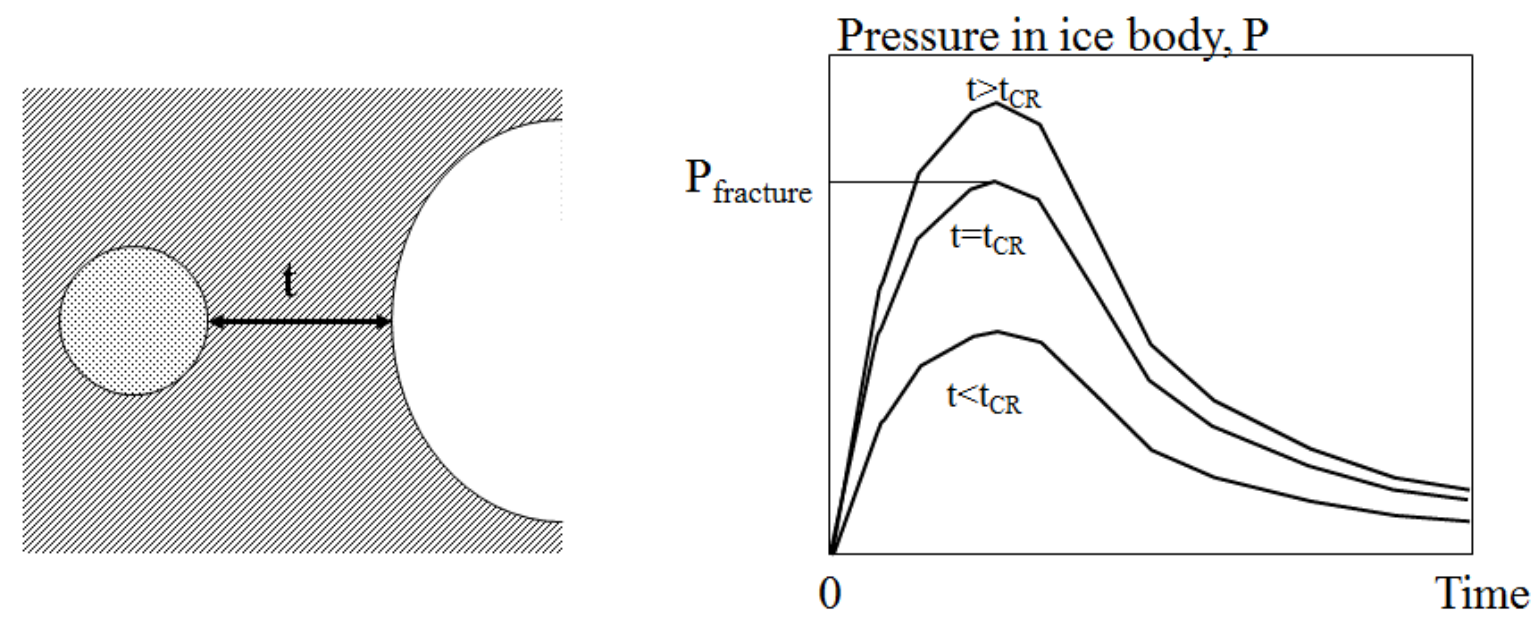

Figure 8 - Hypothetical pressure time curves for different values of the distance $t$ between an ice-filled pore and the nearest air-filled pore.

2: The fact that expansion of moisture insulated concrete containing water content above critical stops when temperature is held constant. As seen by Figure 4 ice formation stops when temperature is held constant.

3: The fact that contraction takes place when water content is below critical, Figure 2 (upper figure) and Figure 3 (lower figure). According to theory, drying caused by transfer of water to ice would cause contraction. However, drying before ice growth stops is rather small as calculated by Equation (24) and could therefore hardly explain the big contractions observed. An alternative explanation to the big contraction is the composite material model described in paragraph 3, viz. the fact that he contraction coefficient of ice is bigger than that of unfrozen material, Equation (10). This is demonstrated by Examples 6 and 7.

\section{Example 6:}

The following data are valid for the cement paste in Figure 2 (upper figure): $V_{\mathrm{i}}$ and $V_{\mathrm{m}}$ vary with temperature, for $-10^{\circ} \mathrm{C}$ the following values are approximately valid, $V_{i}=0.22, V_{\mathrm{m}}=0.78, E_{\mathrm{i}} \approx$ $10 \mathrm{GPa}, E_{\mathrm{m}} \approx 3 \mathrm{GPa}$. This gives:

$$
\alpha \approx \frac{50 \cdot 10^{-6} \cdot 0.22 \cdot 10 \cdot 10^{9}+10 \cdot 10^{-6} \cdot 0.78 \cdot 3 \cdot 10^{9}}{0.22 \cdot 10 \cdot 10^{9}+0.78 \cdot 3 \cdot 10^{9}}=29 \cdot 10^{-6}
$$

Thus, the contraction coefficient for frozen cement paste is about 3 times higher than that of unfrozen material. But, the observed contraction coefficient is also about $30 \cdot 10^{-6} \mathrm{~m} / \mathrm{m}$. This means that most of the contraction coefficient observed might depend on contraction of ice and not on drying caused by water transfer to ice in capillaries or air-pores. 


\section{Example 7:}

An additional example of this composite material effect is seen in Figure 9 showing the temperature time curve of a hard-burnt clay brick frozen below its critical degree of saturation. This is a material with negligible moisture shrinkage, but despite this the thermal shrinkage at minus temperature is big. The following data are valid: $V_{\mathrm{i}}=0.21$ (all ice is formed in the interval $\left.0-5^{\circ} \mathrm{C}\right), V_{\mathrm{m}}=0,79, E_{\mathrm{m}}=20 \mathrm{GPa}, \alpha_{\mathrm{m}}=8 \mathrm{GPa}$. The theoretical contraction coefficient at freezing temperature is:

$$
\alpha \approx \frac{50 \cdot 10^{-6} \cdot 0.21 \cdot 10 \cdot 10^{9}+8 \cdot 10^{-6} \cdot 0.79 \cdot 20 \cdot 10^{9}}{0.21 \cdot 10 \cdot 10^{9}+0.79 \cdot 20 \cdot 10^{9}}=13 \cdot 10^{-6} \frac{\mathrm{m}}{\mathrm{m}}
$$

This is $60 \%$ higher than for unfrozen material. The observed contraction coefficient of frozen material is $15 \cdot 10^{-6} \mathrm{~m} / \mathrm{m}$.

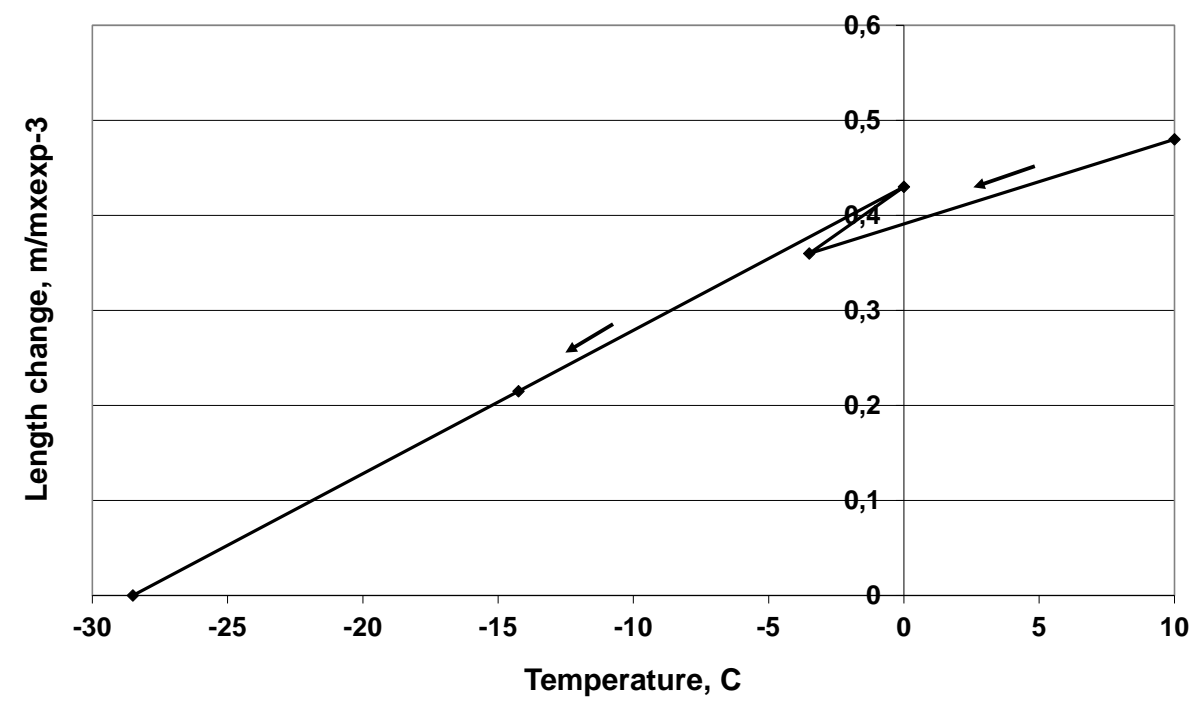

Figure 9 - Length change-temperature curve of hard-burnt clay brick during freezing. Degree of saturation is 0.68 . Critical degree of saturation is 0.75 . Porosity is 0.31 .

\section{6}

\section{Effect of the water-cement ratio}

The amount of unfrozen water required for ice growth in concrete with water content high enough to cause frost damage is big for all w/c- ratios, see Table 1 . However, the water flow needed for ice growth to stop by high water under-pressure is more restricted the lower the w/cratio. Water transport needed for decreasing relative humidity from $100 \%$ to $95 \%$ and $90 \%$ are given in Table 1.

Table 1- Unfrozen water, $w_{\mathrm{nf}} \mathrm{kg} / \mathrm{m}^{3}$ at $-10^{\circ} \mathrm{C}$ based on measurements in [13]. Moisture flow $\Delta \mathrm{w} \mathrm{kg} / \mathrm{m}^{3}$ required to lower $\mathrm{RH}$ to $95 \%$ and $90 \%$. Based on desorption isotherms in [14].

\begin{tabular}{ccccc}
\hline w/c & \multicolumn{3}{c}{$\begin{array}{c}w_{\mathrm{nf}} / \mathrm{c}^{1)} \\
\text { dried and re-saturated }^{3)}\end{array}$} & $\begin{array}{c}\text { moisture flow to reduce } \mathrm{RH} \text { in pores, } \Delta \mathrm{w} / \mathrm{c} \\
100 \% \text { to } 95 \%\end{array}$ \\
\hline 0.3 & 0.19 & 0.09 & 0.02 & 0.03 \\
0.4 & 0.26 & 0.12 & 0.04 & 0.06 \\
0.6 & 0.36 & 0.18 & 0.09 & 0.13 \\
0.8 & 0.42 & 0.23 & 0.16 & 0.22 \\
\hline
\end{tabular}

1) $\mathrm{c}$ is the cement content, $\mathrm{kg} / \mathrm{m}^{3}$. 
2) Saturated, never dried.

3) Pre-dried at $+105^{\circ} \mathrm{C}$ and then re-saturated.

Normal cement content for concrete with w/c-ratio 0.30 is about $500 \mathrm{~kg} / \mathrm{m}^{3}$. Therefore, according to Table 1, the water flow from $100 \%$ to $95 \%$ RH is $10 \mathrm{liter} / \mathrm{m}^{3}$. The volume expansion when this water freezes is 1 liter $/ \mathrm{m}^{3}$ which gives a volume expansion of concrete of $1 \%$ when it is completely saturated. For concrete with w/c-ratio 0.4, 0.6 and 0.8 and cement contents 400,300 and $250 \mathrm{~kg} / \mathrm{m}^{3}$ the volume expansions are round $1.6,2.7$ and $4.0 \%$. Thus, it seems as the ice growth mechanism might have biggest effect for concrete with normal w/cratio, and will be of less importance for high performance concrete with very low w/c-ratio.

\section{5.}

\section{CONCLUSIONS}

The following frost destruction mechanisms are presented and discussed:

1: Hydraulic pressure occurring when excess water formed by the $9 \%$ volume increase of water when transformed into ice is forced through a narrow and partly ice-filled pore system.

2: Ice growth caused by transfer of unfrozen water to ice bodies in capillaries.

3: Volume expansion of ice during thawing due to hysteresis between ice formation and ice melting.

The validity of different destruction mechanisms is tested by confronting the theories with experimental results.

Both the hydraulic pressure mechanism and the ice growth mechanism predict the existence of a critical flow distance from the place where ice formation takes place to the nearest air-filled pore. This means that critical water contents exist, that besides the critical distance depend on the air-pore size distribution. An example is shown in Figure 1. In a previous article the critical distance was experimentally found to be $0.33 \mathrm{~mm}$ for a concrete with w/c-ratio 0.57, [2]. A theoretical analysis based on the hydraulic pressure mechanism, Equation (5), using measured and realistic data for tensile strength, rate of ice formation and permeability gives a value of the critical flow distance that is of the same order as the observed value. This is an indication of the validity of the hydraulic pressure mechanism. Hydraulic pressure will explain the rapid expansion when super-cooling is interrupted, Equation (9).

Ice growth in capillaries is caused by the appearance of a difference in free energy between ice and unfrozen water, when temperature is lowered. In theory, ice pressure might be high enough to destroy the concrete, particularly if the concrete has possibility to absorb water during the freezing process. For normal moisture conditions, where the structure is protected from moisture uptake during freezing, water transfer to ice-bodies will cause the cement paste to dry. Therefore, hydrostatic tension will appear in unfrozen water, which will reduce pressure and even stop it after rather small drying. Thus, the ice growth mechanism might be most important for concrete with limited moisture shrinkage, Table 1 . The fact that concrete that is unharmed by frost contracts more than normal during freezing is often explained by the drying effect caused by water transfer to ice. It is shown that an additional, and possibly more plausible reason for contraction, might be thermal contraction of ice in pores. Ice in air-pores will grow in stress-free condition and will therefore reduce ice growth in capillaries. Air will therefore protect concrete.

When frozen concrete is heated, un-melted ice in the pore system will expand and possibly cause damage to the concrete. A theory for this is given, Equation (10). The reason why ice is 
present during a big part of the warming process is the big hysteresis between ice formation and melting caused by local super-cooling of water in pores.

\section{Comments:}

The theories presented above relate to freezing in a salt-free environment. Then, damage does primarily take place inside the concrete. When concrete is exposed to salt from outside, like in a salt scaling test, damage does normally take place on the surface as scaling. The theories presented may, however, still be applicable provided the effect of salt ions in pore water is introduced in the theories. Moreover, consideration must also be taken to water and ion flow across the concrete surface during freeze/thaw. A thorough discussion of the salt scaling mechanism is performed in [15].

\section{REFERENCES}

1. Fagerlund G: “A service life model for internal frost damage in concrete,” Report TVBM3119 , Div. of Building Materials, Lund Institute of Technology, Lund, Sweden, 2004.

2. Fagerlund G: "The critical flow distance at freezing of concrete - theory and experiment," Nordic Concrete Research, No. 56, 2017, pp. 35-53.

3. Fagerlund G: "Significance of critical degrees of saturation at freezing of porous and brittle materials," Special Publication SP-47-2 "Durability of Concrete," American Concrete Institute. Detroit, USA, 1973.

4. Fridh K.: "Internal frost damage of concrete. Experimental studies of destruction mechanisms," Report TVBM-1023, Div. of Building Materials, Lund Institute of Technology, Lund, Sweden, 2005.

5. Powers T.C.: "The air requirement of frost-resistant concrete," Highway Research Board Proceedings, No 29, 1949, pp. 184-202.

6. Powers T.C.: "Structure and physical properties of hardened Portland cement paste," J. American Ceramic Soc., Vol 41, 1958.

7. Qian Z., Ye G., Schlangen E., van Breugel K.: "Modeling fracture behaviour of cement paste based on its microstructure", Proceedings, $4^{\text {th }}$ Int. Workshop of Young Doctors in Geomechanics. 21-23 Nov. 2012. École des Ponts ,Paris Tech., Paris, France.

8. Zwolinsky B.J. \& Eicher L.D.: "High-precision viscosity of super-cooled water and analysis of the extended range temperature effect,” J. Phys. Chem., 71(13), 1971.

9. Helmuth R.A.: "Capillary size restriction on ice formation in hardened Portland cement paste," Proceedings, $4^{\text {th }}$ Int. Symposium on Chemistry of Cement. Vol II. Nat. Bureau of Standards, Washington DC., USA, 1960.

10. Malhotra M.V., Painter K.A., Bilodeau A.: "Mechanical properties and freezing and thawing resistance of high strength concrete incorporating silica fume," Cement, Concrete and Aggregate. Vol 9, No 2. ASTM, Washington DC., USA, 1987.

11. Helmuth, R.A., Turk, D. Elastic moduli of hardened Portland cement paste and tricalcium silicate pastes. Highway Research Board, Special report 90, 1966.

12. Powers T.C: "Resistance of concrete to frost at early ages," Proceedings, RILEM Symposium on Winter Concreting, Copenhagen, Denmark, 1956. The Danish National Institute of Building Research. Session C, General report, pp 1-50.

13. Vuorinen J.: "On determination of effective degree of saturation of concrete," Concrete and soil laboratory, Imatran Voima OY. Oulu, Finland, 1973.

14. Nilsson L-O.: "Fuktproblem vid betonggolv" ("Moisture problems in concrete floors"), Report TVBM-3002, Div. of Building Materials, Lund Institute of Technology, Lund, Sweden, 1977. (In Swedish.) 
Nordic Concrete Research - Publ. No. NCR 58 - ISSUE 1 / 2018 - Article 3, pp. 35-54

15. Lindmark S.: "Mechanisms of salt frost scaling of Portland cement-based materials: Studies and hypothesis,” Report TVBM-1017, Div. of Building Materials, Lund Institute of Technology, Lund, Sweden, 1998. 